\title{
Conceptual and Methodological Approaches to Choosing a Method for Marking a Surgical Site for Reconstructive Surgery on the Anterior Abdominal Wall
}

\author{
Serhiy H. Hryvenko, MD, PhD, ScD*; Yuriy A. Semenov MD; Abhijit Mahanta, MD; \\ Fedor N. Ilchenko, MD, ScD; Yuriy V. Artemov, MD, PhD; Andrej A. Dovgan MD, PhD \\ Medical Academy named after S.I. Georgievsky of Vernadsky CFU \\ Simferopol, Crimea
}

\begin{abstract}
This article discusses the effectiveness of the author's method of marking a surgical site (Ukraine patent UA 99427) for surgical treatment of patients with postoperative ventral hernias $(\mathrm{POVH})$. Based on the study of quality of life (QOL) indicators obtained using the SF-36 questionnaire, it was found that the proposed therapeutic tactics for surgical correction of POVH can increase medical, social and aesthetic efficacy to a statistically significant improvement in QOL. (International Journal of Biomedicine. 2020;10(1):41-44.)
\end{abstract}

Key Words: postoperative ventral hernias $\bullet$ surgical site $\bullet$ quality of life

\section{Introduction}

Current trends in the development of medicine put in the range of health problems not only the safety, functionality and social orientation of surgical techniques, but also the aesthetics of the consequences of surgical intervention. ${ }^{(1)}$ Surgeons began paying attention to this problem in the second half of the 20th century. This was facilitated by the development of plastic surgery, as well as an increasing understanding in civilized countries of the importance of the role of human appearance..$^{(2-4)}$

Elimination of defects of the anterior abdominal wall (AAW) takes first place among all planned surgical interventions. A significant percentage of these interventions consists of surgery for postoperative ventral hernias (POVH) ${ }^{(5,6)}$ This category of patients is a constant contingent of surgical hospitals. Thus, over the past 25 years, due to the increase in the number of surgical interventions on the abdominal organs, the frequency of POVH has increased by 9 times or more. ${ }^{(7)}$

Marking a surgical site precedes the main stage of any surgical intervention, including during reconstructive

*Corresponding author: Serhiy H. Hryvenko, MD, PhD, ScD. Medical Academy named after S.I. Georgievsky of Vernadsky CFU, Simferopol, Crimea.E-mail: hryva@mail.ru operations on AAW. ${ }^{(8)}$ Each surgical operation ends with suturing the skin. The skin scar that the patient sees is evaluated precisely from an aesthetic point of view. The quality of the seam and the further formation of the scar, from the standpoint of aesthetics, determine the psycho-emotional state of the patient, especially women, for many years.

In this regard, the correct determination and marking of the alleged borders of the excision of the AAW tissues, with the subsequent determination of the symmetry of the applied lines, is of extreme importance from the standpoint of aesthetics and cosmetics. ${ }^{(9,10)}$ Most surgeons mark surgical sites "by eye," which does not allow for achieving the ideal symmetry of the drawn lines, ${ }^{(11,12)}$ thus significantly worsening the cosmetic characteristics of the postoperative scar, the aesthetic consequences of surgery, and as a result, QOL of the patients. Since the perception of one's appearance is one of the key components that forms a patient's satisfaction with a surgery, we consider it worthwhile to study QOL in this category of patients. ${ }^{(13)}$

The purpose of this study was to develop a unified approach to choosing a method for marking a surgical site (access) during reconstructive surgical interventions on AAW, aimed at improving the aesthetic effectiveness of surgical correction and QOL. 


\section{Materials and Methods}

The study was based on a clinical and laboratory examination of 128 patients with $\mathrm{POVH}$ who underwent surgical treatment in the Simferopol Central District Clinical Hospital in the period from 2009 to 2017. The study was carried out in compliance with Ethical Principles for Medical Research Involving Human Subjects, Adopted by the 18th WMA General Assembly, Helsinki, Finland, June 1964, and amended by the 59th WMA General Assembly, Seoul, Republic of Korea, October 2008. Written informed consent was obtained from all patients before inclusion in the study.

All surgical interventions were planned. The examined patients were divided into two groups. Group 1 (comparison group) included 64 patients with POVH who underwent AAW plastic surgery with an allograft according to the "classical" sublay technique and arbitrary marking of surgical access by eye. Group 2 (main group) included 64 patients with similar POVH and cosmetic defects, as well as AAW deformities, who underwent surgical treatment using the author's proposed cutting techniques ${ }^{(14)}$ with allograft fixation ${ }^{(15)}$ when performing retro-muscle hernioplasty. ${ }^{(16)}$ Among the operated patients there were 86 women (67.2\%) and 42 men (32.8\%).

When performing operative access in all cases, wide bordering incisions were considered rational with the complete removal of postoperative scars and the excess skin and subcutaneous fat. The correctly selected shape and direction of the incision create convenient access to a hernial defect and provide a good cosmetic effect. In cases of localization of a hernia or a pathological postoperative scar in the epigastrium, longitudinal and oblique transverse incisions were preferred; in the mesogastrium, longitudinal and transverse incisions; and in the hypogastrium, a T-shaped incision with complete removal of the cutaneous-subcutaneous apron and removal or relocation of the navel.

When determining the width of the carved skin flap, we were guided by the rule: with longitudinal access, the maximum width of the flap should be such that the skin fold on the right side meets without tension the skin fold on the left side when the skin is drawn together by the index fingers along the line of the proposed incision; with horizontal access, respectively, the upper skin fold should meet the lower without tension.

Considering the above-mentioned, a method for marking a surgical site for reconstructive surgery on AAW was proposed, which is carried out as follows: ${ }^{(16)}$ Preoperative marking of the surgical site is carried out with the patient in the vertical position, when the soft tissue of AAW go down under the influence of gravity. We mark the midline from the xiphoid process through the navel to the pubic symphysis, and the transverse line connecting the anterior superior iliac spine of the iliac wing on both sides (Fig.1).

Given the individual mobility of the skin-fat layer, the surgeon, with an assistant, pulls the ligature through the midline between the opposite symmetrical parts of the abdomen above the skin-fat flap and marks the upper access line along a ligature (Fig.2). Similarly, the lower access line is marked on the skin-fat flap (Fig.3). At the end of the marking, the surgeon once again determines the symmetry of the drawn lines (Fig.4) and, creating with the fingers a skin-fat fold on AAW, determines the coincidence of the upper and lower surgical access lines.

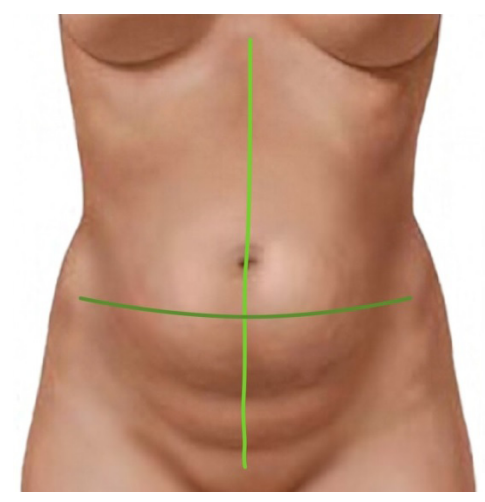

Fig.1. Marking the midline from the xiphoid process through the navel to the pubic symphysis, and the transverse line connecting the anterior superior iliac spine of the iliac wing on both sides

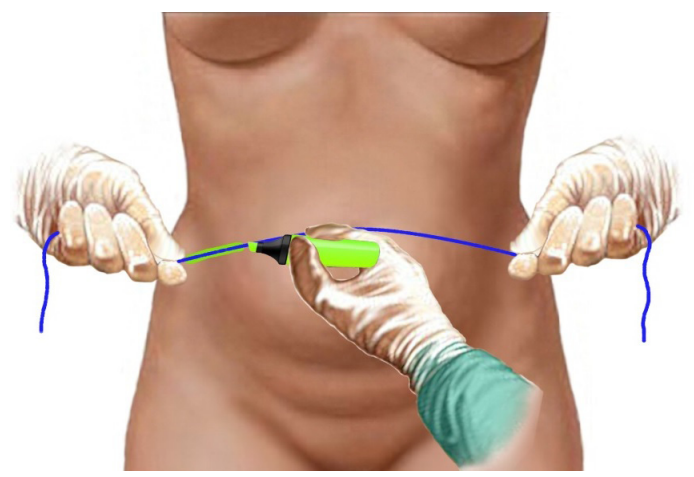

Fig.2. Marking the upper access line along a ligature

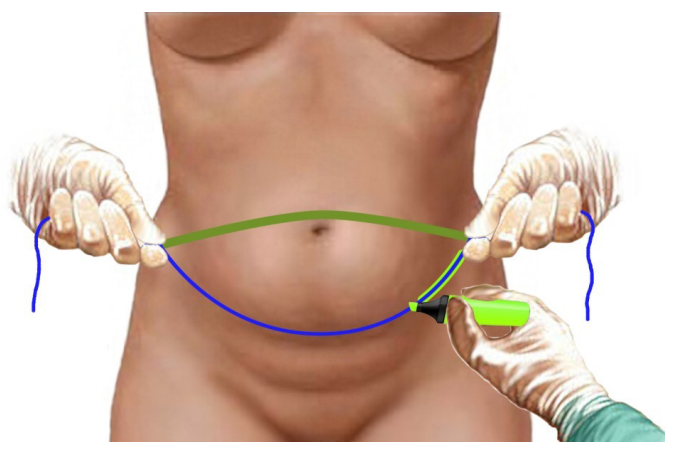

Fig.3. Marking the lower access line along a ligature

It is necessary to make sure that the edges of the future wound will be "without tension," including both in the "direct" (Fig.4) and in the "lateral" projections (Fig.5).

The features of the course of the remote postoperative period were studied in the period from 1 year to 3 years. In order to evaluate QOL after surgical treatment in patients of both clinical groups, we analyzed 128 questionnaires. The QOL of patients was assessed using the MOS SF-36 questionnaire (translation into Russian, validation and testing - Institute of 
Clinical and Pharmacological Research, St. Petersburg), which is a universal standardized questionnaire intended for use in clinical practice and for scientific research. ${ }^{(17)}$ The SF-36 measures eight scales: physical functioning (PF), role physical (RP), bodily pain (BP), general health $(\mathrm{GH})$, vitality (VT), social functioning (SF), role emotional $(\mathrm{RE})$, and mental health $(\mathrm{MH})$.
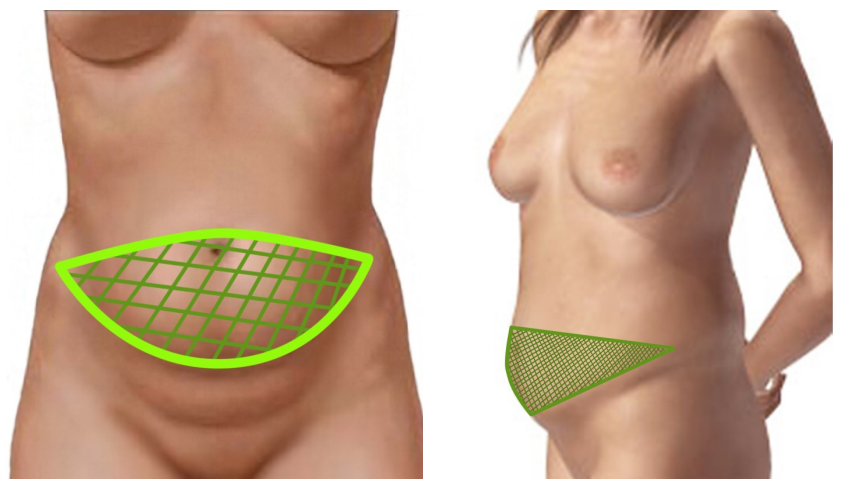

Fig.4. The final view of the marking Fig.5. The final view of the marking of surgical site (in the "direct" of surgical site (in the "lateral" projection) during reconstructive projection) during reconstructive surgical interventions on $A A W \quad$ surgical interventions on $A A W$

The statistical analysis was performed using the statistical software Microsoft Excel 2010. The mean (M) and standard error of the mean (SEM) were calculated. Student's unpaired and paired t-tests were used to compare average values for data with normal distribution. A probability value of $P<0.05$ was considered statistically significant.

\section{Results and Discussion}

When analyzing these questionnaires, it was noted that in the remote postoperative period, the QOL of patients in both clinical groups was high. However, in the comparison group, QOL indicators were significantly lower than in patients of the main group. After 1 year (Table 1), there was an increase in all indicators, reflecting the restoration of working capacity, adaptation to role-based functioning (work, everyday activities), and improvement of emotional well-being. During this period, VT in patients of the main group approached the values of healthy people. SF, RE, and $\mathrm{MH}$ were significantly lower than normal values; therefore, patients experienced certain limitations of social activity, negative emotions and depression due to concomitant neuropsychiatric syndrome. However, in the patients of the main group in the first year, all indicators of QOL were significantly higher than in patients of the comparison group and were practically in the lower values of the norm of healthy indicators.

\section{Table 1.}

QOL indicators in study groups 1 year after surgical treatment

\begin{tabular}{|c|c|c|c|c|c|c|c|c|}
\hline Scales & PF & RP & BP & GH & VT & SF & RE & MH \\
\hline \multirow{2}{*}{ Group 1 } & 65.41 & 62.16 & 67.84 & 61.01 & 48.84 & 72.94 & 72.01 & 66.37 \\
& \pm 0.38 & \pm 0.34 & \pm 0.31 & \pm 0.33 & \pm 0.27 & \pm 0.18 & \pm 0.24 & \pm 0.29 \\
\hline \multirow{2}{*}{ Group 2 } & 67.76 & 64.17 & 69.23 & 63.84 & 51.84 & 75.66 & 74.67 & 69.16 \\
& \pm 0.44 & \pm 0.34 & \pm 0.28 & \pm 0.28 & \pm 0.33 & \pm 0.17 & \pm 0.25 & \pm 0.36 \\
\hline$P$ & $<0.05$ & $<0.05$ & $<0.05$ & $<0.05$ & $<0.05$ & $<0.05$ & $<0.05$ & $<0.05$ \\
\hline
\end{tabular}

After 3 years (Table 2), there was an increase in all indicators, including SF. The VT indicator increased more significantly in the main group than in the comparison group. During this period, none of the patients of both clinical groups changed to easier work, nor did they reduce the level of physical activity. The high rate of increase in the $\mathrm{GH}$ indicator, among other indicators, reflected a certain reassessment of physical strengths, the denial of the disease and the necessary restrictions.

Table 2.

QOL indicators in study groups 3 years after surgical treatment

\begin{tabular}{|c|c|c|c|c|c|c|c|c|}
\hline Scales & PF & RP & BP & GH & VT & SF & RE & MH \\
\hline \multirow{2}{*}{ Group 1 } & 69.30 & 61.08 & 68.53 & 63.80 & 52.83 & 74.37 & 72.64 & 73.33 \\
& \pm 0.24 & \pm 0.13 & \pm 0.12 & \pm 0.18 & \pm 0.15 & \pm 0.30 & \pm 0.29 & \pm 0.21 \\
\hline \multirow{2}{*}{ Group 2 } & 73.06 & 63.09 & 71.44 & 66.78 & 56.22 & 76.05 & 75.01 & 74.31 \\
& \pm 0.29 & \pm 0.11 & \pm 0.16 & \pm 0.19 & \pm 0.32 & \pm 0.23 & \pm 0.25 & \pm 0.28 \\
\hline$P$ & $<0.05$ & $<0.05$ & $<0.05$ & $<0.05$ & $<0.05$ & $<0.05$ & $<0.05$ & $<0.05$ \\
\hline
\end{tabular}

A positive fact is the absence of differences between patients in the study and healthy individuals in the way they characterized their fullness of strength and the absence of depression (VT and MN), because such differences, as a rule, become the background for the development of dissatisfaction with the appearance of the abdomen. Thus, the proposed method for marking a surgical site for surgical treatment of patients with POVH had a positive effect on the QOL of the main group of patients, which made it possible to improve the immediate and long-term results of treatment, increasing both the aesthetic and functional state of the operated patients.

The proposed procedures for the surgical correction of POVH made it possible to increase the medical, social and aesthetic effectiveness to statistically significant improvement in QOL, which makes it possible to recommend the proposed method for marking a surgical site for surgical treatment of patients with POVH, cosmetic defects, and AAW deformities for widespread use in surgical practice.

\section{Competing Interests}

The authors declare that they have no competing interests.

\section{References}

1. Malyk SV, Drabovskiy VS. [Ways of improvement of results plastic operations on the abdominal wall $\backslash$. Svit medicini ta biologii. 2016;3(57):185-189. [Article in Ukrainian].

2. Mageramov DM, Medeubekov USh. [Surgical correction of deformities of the anterior abdominal wall. Reality and Prospects. (Literature review)]. Bulletin of Surgery in Kazakhstan. 2017;1:48-53. [Article in Russian].

3. Shiffman MA, Mirrafati S. Aesthetic Surgery of the Abdominal Wall. Springer-Verlag Berlin Heidelberg; 2005. 4. FurnhamA, Levitas J.Factors thatmotivate people to undergo cosmetic surgery. Can J Plast Surg. 2012;Winter;20(4):e47-50. 5. Parshikov VV, Fedaev AA. [Abdominal Wall Prosthetic Repair in Ventral and Incisional Hernia Treatment: Classification, Terminology and Technical Aspects (Review)]. 
Sovremennye Tehnologii v Medicine. 2015;7(2):138-152. [Article in Russian] doi:10.17691/stm2015.7.2.19

6. Ermolov AS, Koroshvili VT, Blagovestnov DA, Yartsev PA, Shlyakhovsky IA. [Postoperative abdominal hernia: a modern view on incidence and etiopathogenesis]. Hirurgiya. 2017;5:76-82. doi: 10.17116/hirurgia2017576-82. [Article in Russian].

7. Chistiakov DB, Iashchenko AS, Iakovenko TV. [Modern possibility of selecting technologies of hernioplasty in patients with postoperative ventral hernias]. Vestnik Novgorodskogo Gosudarstvennogo Universiteta. 2016;1(92):54-60. [Article in Russian]

8. Uebel CO. Lipoabdominoplasty: Revisiting the Superior Pull-Down Abdominal Flap and New Approaches. Aesth Plast Surg. 2009;33:366-376. doi: 10.1007/s00266-009-9318-z

9. Levesque AY, Daniels MA, Polynice A. Outpatient Lipoabdominoplasty: Review of the Literature and Practical Considerations for Safe Practice. Aesthetic Surgery Journal. 2013;33(7):1021-1029. doi: 10.1177/1090820X13503471

10. Hoyos A, Guarin DE. Ultrasound Assisted Abdominoplasty. Clin Surg. 2017;2:1756.

11. Filho $\mathrm{H}$ da CA, Amorim CCB. Lipoabdominoplasty in the aesthetic treatment of the abdomen: 5 years of experience. Rev Bras Cir Plást. 2012;27(2):301-308.

12. Cucchiaro JV, Lostia H, Velazquez P, Liska E.
Lipoabdominoplasty with Progressive Traction Sutures. Plast Reconstr Surg Glob Open. 2017;5:e1338; doi: 10.1097/ GOX.0000000000001338

13. Drabovsky VS. [Quality of life of patients operated for defects and deformities of anterior abdominal wall evaluated by EUROQOL-5D-5L system in long-term postoperative period]. Aktual'ni problemi suchasnoi medicini. Visnik VDNZU «Ukrains'ka medichna stomatologichna akademiya». 2015;15(1-49):77-80. [Article in Ukrainian].

14. Hryvenko SH, Mel'nichuk IV, inventors; Hryvenko SH, Mel'nichuk IV, assignees. The method for fixation of mesh in hernioplasty of median postoperative ventral hernias. Ukraine patent UA 68574. 2012 March 26. [in Ukrainian].

15. Hryvenko SH, Mel'nichuk IV, inventors; Hryvenko SH, Mel'nichuk IV, assignees. The method of mesh fixation in post-operative ventral hernia retromuscular hernioplasty. Ukraine patent UA 68547. 2012 March 26. [in Ukrainian].

16. Hryvenko SH, Mahanta A, inventors; Hryvenko SH, Mahanta A, assignees. The method for marking surgical access for reconstructive surgery on anterior abdominal wall. Ukraine patent UA 99427. 2015 June 10. [in Ukrainian]. 17. Novik AA, Ionova TI, Gandek B, Suhonos YuA, Kishtovich AV, Cepkova AA. Pokazateli kachestva zhizni naseleniya Sankt-Peterburga. Problemy Standartizacii V Zdravoohranenii. 2001;4:22-31. [Article in Russian]. 